\title{
The Generalized Indicator of the Analysis of Technical and Economic Characteristics of Radio Engineering Means of the Special Purpose
}

\author{
Igor V. Khomenko and Oleg D. Gizatullov* \\ Military Training and Research Center of the Air Force \\ «Air Force Academy ft. Professor N.E. Zhukovsky and Y.A. Gagarin» \\ 54a Starykh Bol'shevikov Str., Voronezh, 394064, Russia
}

Received 04.12.2015, received in revised form 13.03.2016, accepted 27.04.2016

Reliability of an assessment of quality of radar information and contribution of radio engineering means to efficiency of military operations in many respects depends on the indicators chosen for the analysis. In article the new generalized indicator of the technical and economic analysis and a choice of options of creation of land radio engineering means of a special purpose on the basis of convolution of indicators tactical and technical (power) and operational technical characteristics is offered.

Keywords: radar support, performance evaluation, energy characteristics, modernization.

Citation: Khomenko I.V., Gizatullov O.D. The generalized indicator of the analysis of technical and economic characteristics of radio engineering means of the special purpose, J. Sib. Fed. Univ. Eng. technol., 2016, 9(4), 500-512. DOI: 10.17516/1999-494X-2016-9-4-500-512.

(C) Siberian Federal University. All rights reserved

* Corresponding author E-mail address: o77leg@yandex.ru 


\title{
Технико-экономический анализ
}

\section{радиотехнических средств специального назначения}

на основе количественной оценки энергетических

и эксплуатационно-технических характеристик

\author{
И.В. Хоменко, О.Д. Гизатуллов \\ ВУНЦ ВВС «ВВА им. проф. Н.Е. Жуковского и Ю.А. Гагарина» \\ Россия, 371600, Воронеж, ул. Старых большевиков, $54 a$
}

Достоверность оценки качества радиолокаџионной информации и вклада радиотехнических средств специального назначения в эффективность боевых действий во многом зависит от выбранных для анализа показателей. В статье предложен новый обобщенный показатель технико-экономического анализа наземных радиотехнических средств специального назначения на основе свертки показателей тактико-технических (энергетических) $u$ эксплуатационно-технических характеристик.

Ключевые слова: радиолокационное обеспечение, оченка эффективности, энергетические характеристики, модернизация.

Сложность проведения анализа технико-экономических характеристик радиотехнических средств специального назначения (РТC $\mathrm{CH}$ ) для модернизации существующего парка PТC СН состоит в необходимости учета большого количества разнородных показателей, по которым производится оценка различных классов и типов РТС СН [1-4]. В состав РТС СН входят радиолокационные станции (РЛС), радиолокационные комплексы (РЛК) и радиолокационные системы посадки (РСП). Известные подходы к решению задачи сравнительной оценки базируются на основе анализа соответствия показателей качества РТС СН требованиям к качеству радиолокационной информации и использования экспертных оценок для определения весовых коэффициентов для каждого показателя качества РТС СН. При свертке частных показателей в обобщенной показатель присутствует значительная доля субъективизма, привносимая группой экспертов.

Как и в любой сложной системе, выбор технических характеристик РТС СН носит компромиссный характер. В связи с этим оптимизацию параметров систем РТС СН целесообразно осуществлять путем решения многокритериальных многопараметрических задач с учетом возникающих при этом ограничений теоретического и практического характера.

Учитывая многокритериальный и многопараметрический характер этой задачи, наиболее простым и распространенным подходом в этом случае является целенаправленный перебор возможных решений с проверкой полученных результатов по многим критериям, определяющим эффективность работы РТС СН.

Процедура последовательного перебора комплектов параметров требует значительных затрат времени и часто приводит к неоднозначному результату. Окончательный выбор предпочтительного варианта в этом случае должен выполнить наиболее компетентный эксперт - лицо, принимающее решение. Для ускорения процесса перебора вариантов и облегчения выбора

$$
-501-
$$


предпочтительного варианта необходимо разработать обобщенный показатель, позволяющий устранить неопределенность в задаче выбора окончательного решения.

Ориентация оценок на качество решения задач в соединениях (частях) видов ВС РФ с использованием наземных РТС СН (несение боевого дежурства, непрерывное ведение разведки воздушного противника, радиолокационное обеспечение боевых действий зенитных ракетных войск (ЗРВ) и истребительной авиации и др.) также приводит к многокритериальным задачам, методы решения которых разработаны недостаточно.

Модели оценки качества радиолокационной информации и вклада РТС СН в эффективность боевых действий являются хорошим инструментом для технико-экономического анализа РТС СН. Однако результаты оценки эффективности конкретной РЛС могут значительно различаться в зависимости от конкретных условий применения (состав группировки, характеристики налета противника и др.). Поэтому целесообразно сравнивать потенциальные возможности, которые в основном реализованы в зоне обнаружения РЛС, формируемой с учетом энергетических характеристик РЛС [1-3, 5].

Цель статьи - обосновать обобщенный показатель технико-экономического анализа РТС $\mathrm{CH}$.

Под обобщенным показателем понимается показатель, принятый за основу при сравнительной характеристике показателей качества РТС СН. Показатель технико-экономического анализа РТС СН должен связывать энергетические характеристики (дальность обнаружения, точность определения координат, помехозащищенность), надёжностные свойства (безотказность, ремонтопригодность, долговечность), стоимостные характеристики РТС СН (стоимость разработки, производства и эксплуатации) и ресурсные возможности по финансированию.

\section{Энергетические характеристики РТС СН}

Зона обнаружения (3О) $V_{0}$ представляет собой область пространства, в пределах которой

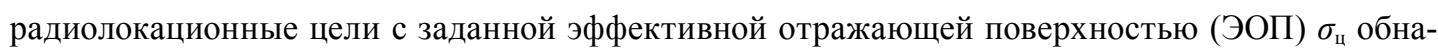
руживаются РТС СН в каждом обзоре с заданными вероятностями правильного обнаружения $D$ и ложной тревоги $F$. Для оперативно-тактических расчетов характеристики 30 принимают величину ЭОП, равной $\sigma_{\text {ц }}=1 \mathrm{M}^{2}, D-0,5$ или 0,8 , а $F$ - в пределах от $10^{-4}$ до $10^{-8}[1,6]$.

Зона обнаружения определяется формой диаграммы направленности антенны (ДНА), дальностью обнаружения РТС СН (энергетическим потенциалом), способом обзора пространства, характеристиками позиции, на которой развернута РТС СН, помеховой обстановкой $[2,4]$. Форма представления 30 может быть: табличная, графическая, аналитическая. Наиболее удобной является графическая форма представления 30 - сечение вертикальной и горизонтальной плоскостями 30 (рис. 1).

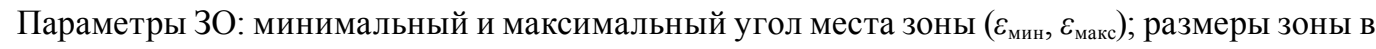

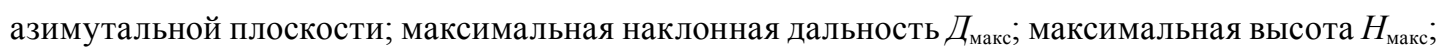
максимальная высота беспровальной проводки (на рис. 1 не показано); радиус «мертвой воронки» на заданной высоте полета цели $R_{\text {мв }}=H_{\text {ц }} \operatorname{ctg} \varepsilon_{\text {макс }}[3,4]$. Параметры 30 выбираются с учетом тактических требований и технических возможностей их реализации.

В качестве примера на рис. $2 a$ показано полусечение 30 РЛС П-18 М в вертикальной плоскости, где 1 - $3 О$ модернизированной РЛС без активных помех; 2 - 30 немодернизированной 


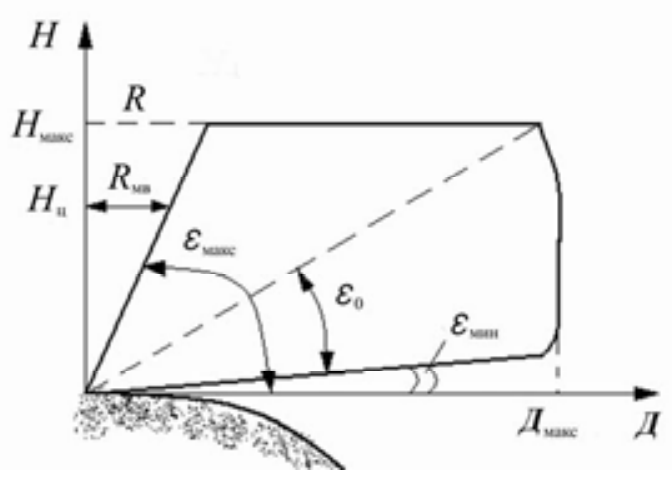

a)

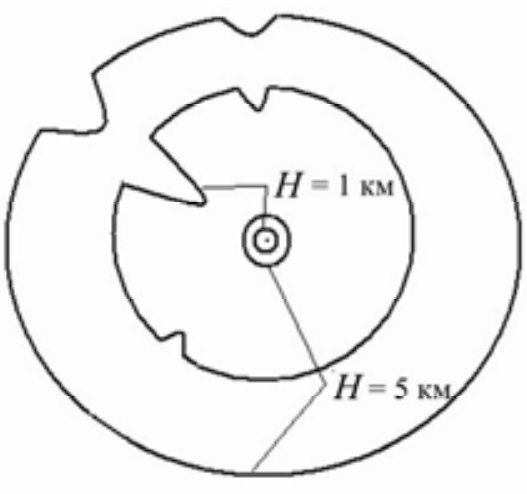

б)

Рис. 1. Полусечение зоны обнаружения РЛС в вертикальной (а) и горизонтальной (б) плоскости

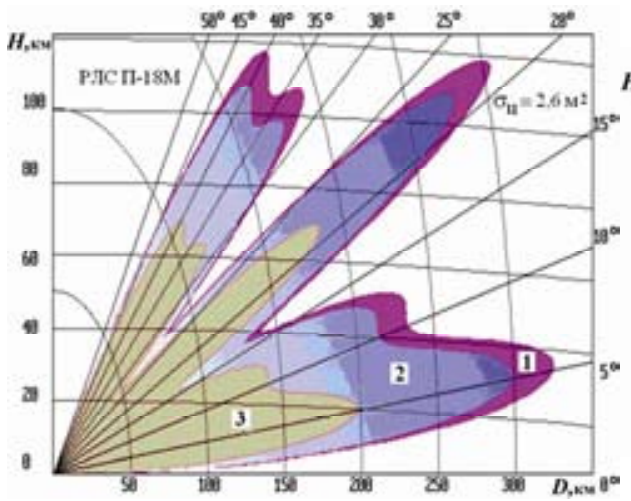

a)

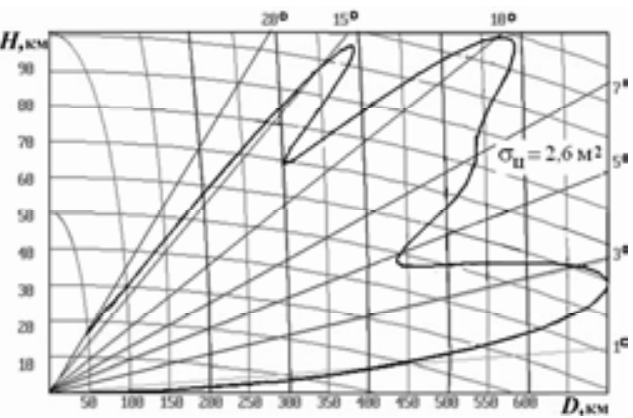

б)

Рис. 2. Полусечение 30 РЛС П-18 М (а) и 55Ж6УЕ (б) в вертикальной плоскости при $\sigma_{\text {ц }}=2,6$ м $^{2}$

РЛС без активных помех; 3 - 30 модернизированной РЛС в условиях воздействия активных шумовых заградительных помех спектральной плотностью 100 Вт/МГц, созданных с дальности 200 км и высоты 10 км. На рис. 26 представлено полусечение 30 РЛС 55Ж6УЕ в вертикальной плоскости при отсутствии активных помех. При этом радиус «мертвой воронки» $R_{\text {мв }}=H_{\text {ц }}$ $\operatorname{ctg} \varepsilon_{\text {макс }}$ соответственно составляет $R_{\text {мв }}=H_{\text {ц }}$ и $R_{\text {мв }}=3,5 H_{\text {ц. }}$.

Для РЛС СН определение зоны обнаружения недостаточно, так как оно не учитывает точности определения координат при решении задач целеуказания. Точность выдаваемой информации определяет вероятность радиолокационного обеспечения наведения в пределах зоны наведения. Зона наведения $V_{\text {н }}$ - это область пространства, в которой обеспечивается непрерывное сопровождение целей и истребителя, измерение их текущих координат с требуемой точностью и уверенное радиолокационное опознавание. В этом случае зону обнаружения и определение координат воздушных объектов (ВО) можно представить в виде пересечения зоны обнаружения и области пространства, в которой координаты ВО определяются с заданной (требуемой) точностью. 
Таким образом, оценить зону обнаружения можно площадью её горизонтального сечения $S_{h}$ на заданной высоте $H$ (рис. 16). Исходя из этого обобщенный критерий оценки качества должен быть пропорционален показателю площади горизонтального сечения зоны обнаружения РЛС.

\section{Эксплуатационно-технические характеристики}

Наряду с энергетическими характеристиками, на основании которых рассчитывается 30 РТС СН, необходимо учитывать эксплуатационно-технические характеристики (ЭТХ), определяющие возможности по реализации боевых возможностей РТС СН. К основным ЭТХ относятся характеристики надежности (безотказность, ремонтопригодность, долговечность), среднегодовая стоимость эксплуатации РТС СН, которая зависит от используемой элементной базы, конструктивных особенностей РТС СН, приспособленности к проведению ремонтов и др. Радиолокационное поле существует в пространстве и во времени, а его пространственные характеристики в конкретный момент времени носят случайный характер. Пространственные характеристики определяются энергетическими возможностями, а процесс их реализации во времени - показателями надежности.

Время существования радиолокационного поля пропорционально ресурсу до списания $R$ (с учетом ресурсовосстанавливающих ремонтов и срока морального старения). Вероятность наличия радиолокационного поля в конкретный момент времени можно оценить коэффициентом готовности РТС СН [1]:

$$
K_{\mathrm{r}}=\frac{T_{0}}{T_{0}+T_{\text {в }}},
$$

где $T_{0}$ - средняя наработка РТС СН на отказ, $T_{\text {в }}$ - среднее время восстановления.

Обобщенный критерий, пропорциональный количеству поставляемых в войска РТС СН $M$, определяется выделяемыми суммарными ассигнованиями $C_{\Sigma}$ на разработку, закупку серийных образцов и эксплуатацию РТС СН:

$$
M=\frac{C_{\Sigma}-C_{\mathrm{p}}}{(1+\alpha) C_{\mathrm{c}}+C_{\ni}},
$$

где $C_{\mathrm{p}}$ - стоимость разработки образца радиоэлектронной техники (РЭТ); $\alpha$ - коэффициент, учитывающий прибыль производства образца на предприятии-изготовителе; $C_{\text {сп }}-$ стоимость серийного образца РЭТ; $C_{\ni}$ - стоимость эксплуатации образца РЭТ до списания.

С учетом вышеизложенного обобщенный показатель качества РТС СН можно представить в виде

$$
W=S_{h} R \frac{T_{0}}{T_{0}+T_{\mathrm{B}}} M
$$

Обобщенный показатель технико-экономического анализа РТС CH $W$ связывает энергетические характеристики (дальность обнаружения $R$, точность определения координат, помехозащищенность), надёжностные свойства (безотказность, ремонтопригодность, долговечность), 
стоимостные характеристики РТС СН (стоимость разработки, производства и эксплуатации) и ресурсные возможности по финансированию $C_{\Sigma}$.

Зона обнаружения РТС СН в сантиметровом диапазоне волн определяется по формуле

$$
D(\varepsilon)=D_{\max } F(\varepsilon),
$$

где $D_{\max }$ - максимальная дальность обнаружения цели с данной ЭОП $\sigma_{\text {u }} F(\varepsilon)$ - нормированная диаграмма направленности антенны РТС СН в вертикальной плоскости; $\varepsilon$ - угол места цели $[1,3,4,6-8]$.

В дециметровом и метровом диапазонах волн диаграмма направленности РТС СН формируется путем сложения энергии прямого луча и энергии, падающей под различными углами на подстилающую поверхность и отраженной в направлении прямого луча. Рельеф и минеральный состав подстилающей поверхности существенно влияют на отражение электромагнитной энергии. Диаграмма направленности РТС СН метрового и дециметрового диапазонов:

$$
D(\varepsilon)=D_{\mathrm{c}} F_{\mathrm{c}}(\varepsilon) \Phi(\varepsilon),
$$

где $D_{\text {c }}$ - максимальная дальность обнаружения $\mathrm{BO}$ с данной ЭОП $\sigma_{\text {в }}$ свободном пространстве; $F_{\mathrm{c}}(\varepsilon)$ - нормированная диаграмма направленности антенны РТС СН в свободном пространстве; $\Phi(\varepsilon)$ - интерференционный множитель (множитель Земли).

Реальные зоны обнаружения РТС СН, развернутых на боевых позициях, рассчитываются с учетом влияния рельефа местности и проверяются облетом. В процессе эксплуатации РТС $\mathrm{CH}$ накапливается статистика обнаружения целей на данной позиции на различных высотах и с различными ЭОП, на основании которой зона обнаружения уточняется.

На рис. 3. представлено полусечение $3 О$ РЛС «Каста-2Е2» в вертикальной плоскости при $\sigma_{\text {ц }}=1 \mathrm{M}^{2}$ без учета (тонкая линия) и с учётом (жирная линия) влияния рельефа местности и подстилающей поверхности.

На рис. 4 изображены полусечения 3 трех РЛС «Каста-2Е2» в горизонтальной плоскости, полученные при различных условиях: а) рассчитанное без учета влияния рельефа местности и подстилающей поверхности); б) при размещении на позициях, выбранных из общих требований (без детального учета рельефа и подстилающей поверхности); в) построенные с учётом особенностей рельефа местности и подстилающей поверхности (РЛС удалены не более 5 км от первоначального положения); г) сопоставление радиолокационных полей (РЛП) станций, размещаемых без учета и с учетом особенностей рельефа местности и подстилающей поверхности. Из рис. 4ح видно, что площадь РЛП РЛС, размещаемых с учетом рельефа, существенно больше.

Площадь горизонтального сечения зоны обнаружения вычисляют по формуле

$$
S_{h}\left(V_{0}\right)=\pi D^{2}(\varepsilon)-S_{\mathrm{MB}},
$$

где $S_{\text {мв }}$ - площадь горизонтального сечения «мертвой воронки» зоны обнаружения РЛС.

Площадь горизонтального сечения мёртвой воронки определяется формулой

$$
S_{\mathrm{MB}}=\pi \cdot R_{\mathrm{MB}}^{2}=\pi\left(H_{\mathrm{u}} \operatorname{ctg} \varepsilon_{\max }\right)^{2},
$$

где $H_{\text {ц }}$ - высота полёта воздушного объекта; $\varepsilon_{\max }$ - максимальный угол места диаграммы направленности РЛС.

$$
-505-
$$




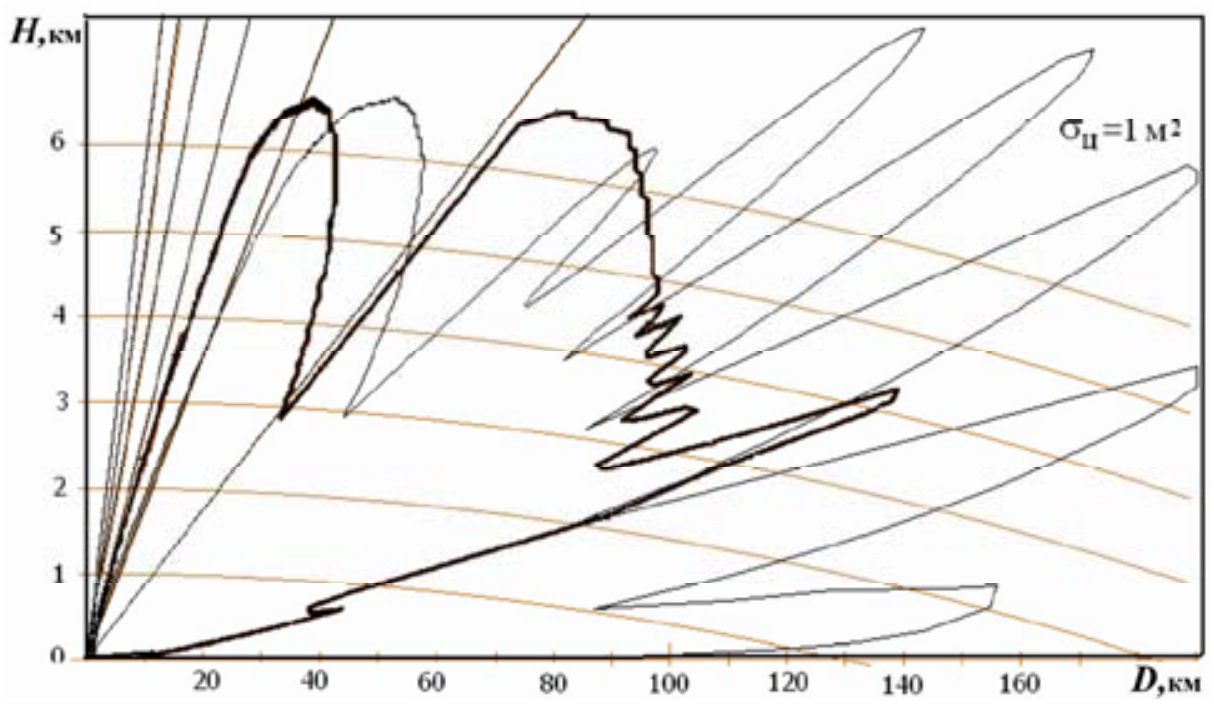

Рис. 3. Полусечение 30 РЛС «Каста-2Е2» в вертикальной плоскости при $\sigma_{\text {щ }}=1$ м $^{2}$

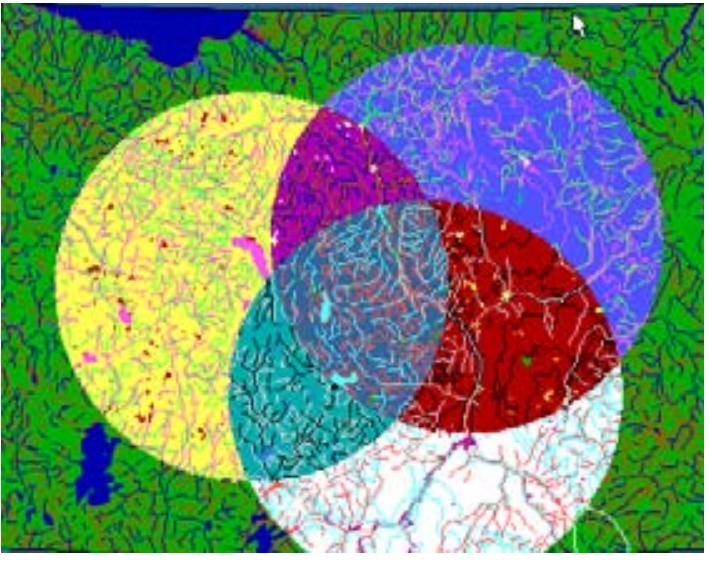

a)

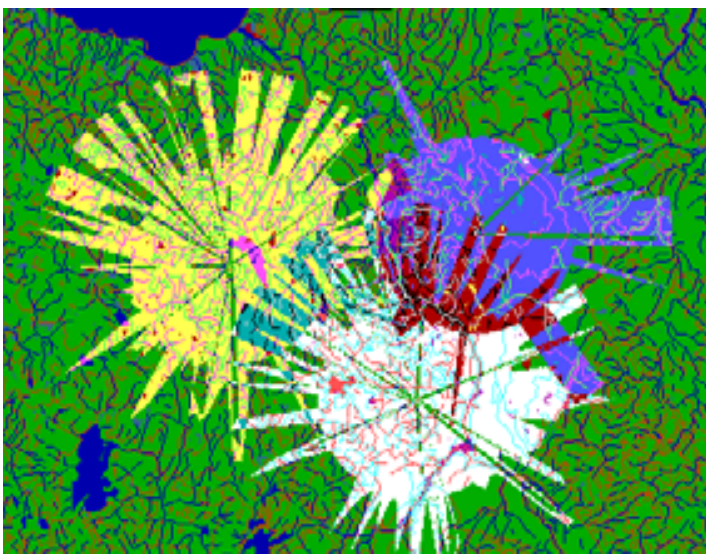

B)

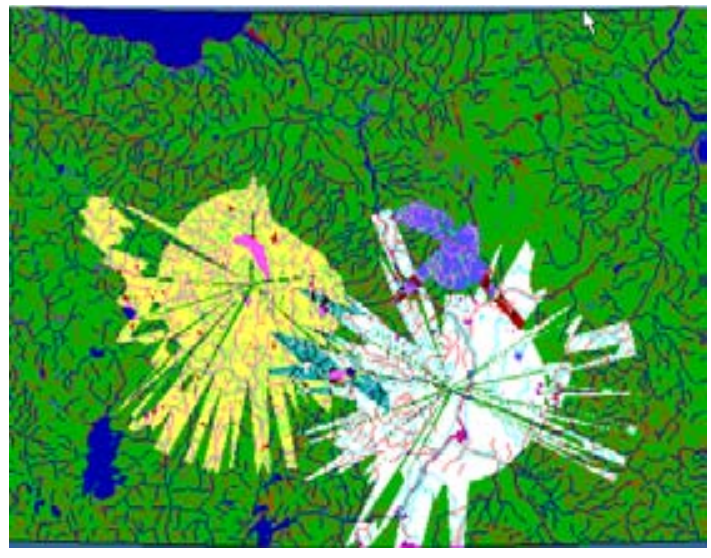

б)

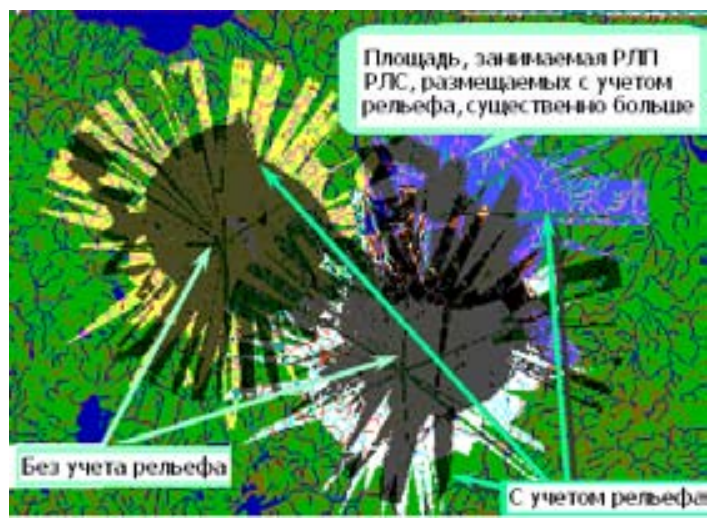

г)

Рис. 4. Полусечения 30 трех РЛС «Каста-2Е2» в горизонтальной плоскости при $\sigma_{\text {ц }}=1$ м $^{2}$ (высота 100 м) 
Максимальная дальность обнаружения РЛС в свободном пространстве определяется выражением

$$
D_{\text {С }}=\sqrt[4]{\frac{P_{\text {и }} G_{0}^{2} \lambda^{2} \sigma_{\text {ц }}}{(4 \pi)^{3} P_{\text {пр. } \min } q L_{\text {п }}}},
$$

где $P_{\text {и }}-$ импульсная мощность; $G_{0}-$ коэффициент усиления антенны; $\lambda$ - длина волны; $\sigma_{\text {ц }}-$ эффективная отражающая поверхность цели; $P_{\text {пр.min }}-$ чувствительность приёмника; $q$ - параметр обнаружения; $L_{\text {п }}$ - результирующий коэффициент потерь [8].

Коэффициент усиления антенны $G_{0}$ вычисляется по формуле

$$
G_{0}=4 \pi S_{\text {эф }} / 2 \lambda
$$

где $S_{\text {эф }}=K_{\text {и }} S_{\text {геом }}$ - эффективная площадь антенны; $S_{\text {геом }}$ геометрическая площадь антенны; $K_{\text {и }}$ - коэффициент использования площади антенны (для различных типов антенн $K_{\text {и }}=0,5 \div 0,7$ ); $\lambda$ - длина волны.

Коэффициент потерь $L_{\text {п }}$ учитывает различного рода потери в передающем и приёмном трактах РЛС. В общем виде результирующий коэффициент потерь можно представить как произведение

$$
L_{\text {п }}=\prod_{i} L_{i},
$$

где $L_{i}$ - частные коэффициенты, характеризующие потери в различных элементах РТС СН [2, 4]. Расчёт коэффициентов потерь $L_{i}$ является специфической задачей, учитывающей особенности каждого конкретного радиотехнического средства.

Суммарные потери сигнала состоят из потерь в волноводных, передающих и приемных трактах, потерь на обработку, потерь в атмосфере и составляют 12-15 дБ.

Для РЛК 5Н87М суммарные потери сигнала $L_{\text {п }}$ равны 12,7 дБ, затухание в атмосфере 0,9 дБ и состоят из потерь [10]: в передающем тракте - 2,5 дБ (включают потери в циркуляторе $(0,7$ дБ), коммутаторе (0,2 дБ), фильтре гармоник (0,8 дБ), волноводе $(0,3$ дБ) и потери на отражение $(0,5$ дБ)); в приемнике ВЧ тракта - 2,4 дБ (включают потери в выключателе $(0,9$ дБ), фильтре (1 дБ) и кабеле $(0,5$ дБ)); на обработку - 6,1 дБ (включают потери за счет временной дискретизации (3 дБ), амплитудного квантования $(0,1$ дБ), потери при суммировании парциальных каналов (0,6 дБ), потери на сканирование в азимутальной плоскости $(1,6$ дБ) и максимальные потери из-за доплеровского смещения частоты (0,8 дБ).

Для РЛС 1Л117М суммарные потери сигнала $L_{\text {п }}$ составляют 13,8 дБ (24 раз), затухание в атмосфере 1,5 дБ (нижний луч), 1 дБ (верхний луч) и состоят из потерь [10]: в приемном тракте (1,6 дБ); в передающем тракте (2 дБ); на искажение формы импульса $(1,4$ дБ); на дискретизацию (1,4 дБ); на взвешивание (1,4 дБ); на сжатие (2,5 дБ) и прочие потери (2 дБ).

Возможности РЛС по ведению разведки в пассивных помехах определяются аппаратурой селекции движущихся целей (СДЦ), которые являются неотъемлемой частью современных РТС СН. В когерентно-импульсных радиолокационных системах аппаратура СДЦ выполняется в виде устройств фазового сравнения зондирующих и отраженных сигналов с последующей обработкой результата сравнения цифровыми нерекурсивными фильтрами первого, второго и

$$
-507-
$$


третьего порядка с целочисленными масштабными коэффициентами или адаптивными трансверсальными фильтрами более высокого порядка с комплексными перестраиваемыми масштабирующими коэффициентами [8].

Вероятность обнаружения ВО и, следовательно, 30 наземных РТС СН в значительной степени определяется эффективностью работы систем СДЦ. На качество работы этих систем влияют такие факторы, как амплитудная и фазовая модуляции отраженных сигналов, возникающие при обзоре пространства вращающейся узкой диаграммой направленности антенны, флуктуации эффективной отражающей площади целей, нестабильность параметров аппаратуры РТС СН, кратность вычитания сигналов в компенсаторе, дополнительное расширение спектра помех за счет вобуляции периода повторения зондирующих импульсов и ограничения сигналов в приемном тракте радиолокатора и т. д. Многие из этих факторов зависят не только от технических параметров радиолокаторов, но и от условий внешней среды, в которой работает радиолокатор.

В настоящее время для оценки эффективности систем СДЦ используют несколько критериев. В зависимости от решаемой задачи в качестве энергетических критериев могут быть приняты: коэффициент подавления пассивной помехи $K_{\text {п }}$ и коэффициент улучшения $K_{\mathrm{y}}$; коэффициент подпомеховой видимости $K_{\text {пв }}$, коэффициент различимости цели на фоне пассивных помех, коэффициент различимости цели в просветах пассивных помех и др. [2-5, 8, 9].

Из указанных выше критериев наиболее часто используют коэффициенты подавления, улучшения и подпомеховой видимости, которые связаны с $K_{\text {п }}$ и $K_{\mathrm{y}}$ :

$$
\begin{aligned}
& K_{\text {п }}=P_{\text {пвх }} / P_{\text {пвых }} ; \\
& K_{\text {у }}=K_{\text {п }} \bar{K}_{\mathrm{cp}} ; \quad \bar{K}_{\mathrm{cp}}=\int_{-F_{\Pi} / 2}^{F_{\mathrm{n}} / 2} K^{2}(f) d f=P_{\text {Швых }} / P_{\text {Швх }},
\end{aligned}
$$

где $K_{\text {п }}$ - отношение мощности пассивной помехи на входе системы СДЦ к мощности на его выходе; $K_{\mathrm{y}}$ - средний коэффициент усиления мощности сигнала или коэффициент усиления шума.

Коэффициент подпомеховой видимости:

$$
K_{\text {пв }}=K_{\mathrm{y}} / q_{\text {пор }} ; K_{\text {пв }}[д Б]=K_{\text {у }} / q_{\text {пор }},
$$

где $q_{\text {пор }}=\left(\bar{P}_{\mathrm{c}} / P_{\text {п }}\right)_{\text {вхобн }}-$ пороговое отношение сигнал-помеха на входе обнаружителя, усредненное по всем доплеровским частотам и представляющее собой минимальное превышение сигнала над помехой, необходимое для обнаружения цели. При расчете коэффициентов $K_{\mathrm{y}}$ и

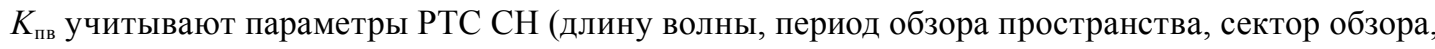
частоту повторения импульсов, ширину диаграммы направленности антенны, коэффициент вобуляции периода повторения импульсов, кратность вычитания сигналов, нестабильность внутренних параметров РТС СН, параметры аналогоцифровых преобразователей, наличие ограничений сигнала в приемном тракте, тип когерентности опорного генератора) и параметры местных предметов (средний квадратический разброс скоростей элементарных отражателей). Сопоставляя величину коэффициента подпомеховой видимости $K_{\text {пв }}$ с реальным отношением мощности сигналов пассивных помех к мощности эхо-сигналов, которое характерно для райо- 
на дислокации, делают вывод о способности РТС СН вести разведку в пассивных помехах в данной помеховой обстановке [3, 4].

Возможности по защите от активных шумовых помех характеризуются величиной коэффициента сжатия зоны обнаружения по нешумящим целям вне сектора эффективного подавления и размерами сектора эффективного подавления по шумящим целям (постановщикам активных шумовых помех).

В основу расчета параметров РЛП можно положить определение зоны видимости (3В) РТС СН группировки РТВ. Методики расчета рубежей и границ ЗВ включают построение их сечений поверхностями, образуемыми множеством возможных траекторий полета цели на заданных высотах относительно уровня моря и/или рельефа (далее для краткости - сечения ЗВ на заданной высоте). Высоты верхней и нижней границ сплошного РЛП можно получить путем объединения сечений ЗВ РТС СН группировки.

Для расчета дальности обнаружения на заданной высоте применяют способы графоаналитического и дискретно-последовательного анализа, которые включают построение ЗВ РТС СН группировки РТВ на основе последовательной проверки выполнения условий обнаружения цели над элементарными участками местности (ЭУМ), на которые предварительно разбивается весь район ответственности группировки РТВ.

\section{Анализ профиля местности}

Реализация проверки факта обнаружения цели включает анализ профиля местности «РЛС - цель». Сканирование профиля местности сводится к определению его промежуточных точек с использованием следующих параметрических уравнений:

$$
\left\{\begin{array}{l}
L_{i}(\Delta L)=L_{0}+\Delta L \\
B_{i}(\Delta L)=B_{i}\left(L_{i}(\Delta L)\right),
\end{array}\right.
$$

где $B_{0}, L_{0}$ - географические координаты начальной точки профиля; $B_{k}, L_{k}$ - географические координаты конечной точки профиля; $B_{i}, L_{i}$ - географические координаты промежуточной точки профиля; $\Delta L$ - произвольное приращение географической долготы.

$$
\begin{aligned}
& B_{i}=\operatorname{arctg} \frac{z_{i}}{a\left(1-e^{2}\right) \sqrt{1-\frac{z_{i}^{2}}{b^{2}}}} ; z_{i}=\frac{z_{\perp}+k_{r} \sqrt{\left(1+\frac{k_{r}^{2}}{b^{2}}\right)-\frac{z_{\perp}^{2}}{b^{2}}}}{1+\frac{k_{r}^{2}}{b^{2}}} ; k_{r}=\frac{a\left(z_{i}^{\prime}-z_{\perp}\right)}{\sqrt{x_{i}^{\prime 2}+y_{i}^{\prime 2}}} ; \\
& z_{\perp}=-\frac{a e^{2} \sin B_{0}}{\sqrt{1-e^{2} \sin ^{2} B_{0}}} ; \quad x_{i}^{\prime}=\frac{\cos L_{i}\left(y_{0}-k_{y} x_{0}\right)}{\sin L_{i}-k_{y} \cos L_{i}} ; \quad y_{i}^{\prime}=k_{y}\left(x_{i}^{\prime}-x_{0}\right)+y_{0} ; z_{i}^{\prime}=k_{z}\left(x_{i}^{\prime}-x_{0}\right)+z_{0} ; \\
& k_{y}=\frac{y_{k}-y_{0}}{x_{k}-x_{0}} ; \quad k_{z}=\frac{z_{k}-z_{0}}{x_{k}-x_{0}} ; \\
& x_{0}=N_{0} \cos B_{0} \cos L_{0} ; \quad y_{0}=N_{0} \cos B_{0} \sin L_{0} ; \quad z_{0}=N_{0}\left(1-e^{2}\right) \sin B_{0} ; \\
& N_{0}=\frac{a}{\sqrt{1-e^{2} \sin ^{2} B_{0}}} ; \quad x_{k}=N_{k} \cos B_{k} \cos L_{k} ; \quad y_{k}=N_{k} \cos B_{k} \sin L_{k} ; z_{k}=N_{k}\left(1-e^{2}\right) \sin B_{k} ; \\
& N_{k}=\frac{a}{\sqrt{1-e^{2} \sin ^{2} B_{k}}},
\end{aligned}
$$


где $a, b, e^{2}$ - параметры эллипсоида (соответственно размеры большой и малой полуоси и первый эксцентриситет).

При сканировании профиля вычисляется максимальный угол закрытия:

$$
\alpha_{s}=\operatorname{arctg}\left(\frac{h_{s}+z_{s}-h_{\text {эца }}}{d_{s}}-\frac{d_{s}}{2 R_{\ni}}\right),
$$

где $h_{s}$ - абсолютная высота ЭУМ; $Z_{s}$ - относительная высота ЭУМ; $d_{s}$ - удаление точки от радиолокационного средства; $R_{\ni}$ - эквивалентный радиус Земли $\left(R_{\ni}=8500\right.$ км$) ; h_{\text {эца }}$ высота электрического центра антенны (ЭЦА).

Для проверки факта обнаружения цели угол закрытия сравнивается с углом места цели, вычисляемым по формуле

$$
\varepsilon_{\text {ц }}=\operatorname{arctg}\left(\frac{h_{\text {ц }}-h_{\text {эца }}}{\bar{D}_{\text {ц }}}-\frac{\bar{D}_{\text {ц }}}{2 R_{\text {э }}}\right),
$$

где $\bar{D}_{\text {u }}$ - плоскостная дальность цели.

В случае видимости цели из геометрических соображений производится проверка факта видимости цели с учетом технических возможностей станции и дальности прямой видимости $[1,4]$ :

$$
\begin{aligned}
& D_{\text {обн }}\left(\beta_{\text {ц }}, \varepsilon_{\text {ц }}\right)=\min \left\{D_{\text {дн }}\left(\varepsilon_{\text {ц }}\right), D_{\text {инд }}, D_{\text {пв }}\left(\beta_{\text {ц }}\right)\right\} ;
\end{aligned}
$$

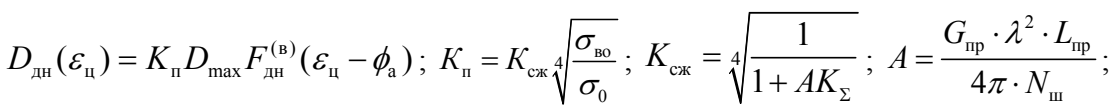

$$
\begin{aligned}
& K_{\Sigma}=10^{13} \cdot \eta_{N} \cdot \sum_{i=1}^{N} \frac{\rho_{n i}}{R_{n i}^{2}} \cdot F_{\text {дн }}^{(\mathrm{s})}\left(\varepsilon_{i}\right) \cdot F_{\text {дн }}^{(\mathrm{r})}\left(\beta_{i}\right),
\end{aligned}
$$

где $\sigma_{\text {во }}-$ ЭОП ВО, $\sigma_{0}=1 ; G_{\text {пр }}$ - коэффициент усиления приемной антенны радиолокационного средства; $\lambda$ - длина волны радиолокационного средства, м; $L_{\text {пр }}$ - коэффициент потерь в приемном тракте радиолокационного средства; $N_{\text {шI }}$ коэффициент шума приемника радиолокационного средства; $\eta_{N}-$ коэффициент подавления помех автокомпенсационной аппаратурой радиолокационного средства при воздействии $N$ источников активной шумовой помехи (АШП); $N$ - количество источников АШП, воздействующих на радиолокационное средство; $\rho_{i}-$ плотность мощности помех, создаваемая $i$-м постановщиком активной помехи (ПАП) для радиолокационного средства; $R_{\text {пi }}$ - удаление $i$-го ПАП от радиолокационного средства; $F_{\text {дн }}^{(\text {в) }}\left(\varepsilon_{i}-\phi_{\mathrm{a}}\right)-$ значение нормированной ДНА радиолокационного средства в вертикальной плоскости в направлении на $i$-й источник АШП; $\varepsilon_{i}$ - угол места $i$-го источника АШП; $\phi_{\text {a }}$ - угол наклона фокальной оси антенны радиолокационного средства; $F_{\text {дн }}^{(\mathrm{r})}\left(\beta_{i}\right)$ - значение нормированной ДНА радиолокационного средства в горизонтальной плоскости в направлении на $i$-й источник АШП; $\varepsilon_{i}-$ азимут визирования $i$-го источника АШП;

$$
D_{\text {пв }}\left(\beta_{\text {u }}\right)=\left\{\begin{array}{c}
K_{\text {и }} \sqrt{2 R_{э}}\left(\sqrt{h_{\text {u }}}+\sqrt{h_{\text {эца }}}\right), \text { для грубого расчета } \\
\sqrt{\left(K_{\text {и }}^{2} R_{\ni} \sin \alpha_{\text {max }}\left(\beta_{\text {u }}\right)\right)^{2}+2 K_{\text {и }}^{2} R_{э}\left(h_{\text {u }}-h_{\text {эца }}\right)}-K_{\text {и }}^{2} R_{\ni} \sin \alpha_{\text {max }}\left(\beta_{\text {u }}\right), \\
\text { для других способов расчета } \\
-510-
\end{array}\right.
$$


где $\alpha_{\max }\left(\beta_{\text {ц }}\right)$ - максимальный угол закрытия по азимуту визирования цели; $K_{\text {и }}-$ коэффициент использования радиогоризонта; $D_{\text {инд }}$ дальность, соответствующая максимальному масштабу индикатора радиолокационного средства.

Оценка стоимости эксплуатации РТС СН может проводиться по методике, учитывающей затраты на услуги промышленности, стоимости израсходованного в течение года эксплуатации запасных инструментов и принадлежностей, капитального, среднего (фирменного) ремонтов из расчета затрат на один год, текущего ремонта, израсходованной электроэнергии, содержания обслуживающего персонала, расходных материалов при проведении технического обслуживания и ремонта и транспортные расходы.

\section{Заключение}

Предложенный новый обобщенный показатель технико-экономического анализа и выбора вариантов построения РТС СН основан:

на количественной оценке потенциальных возможностей РТС $\mathrm{CH}$, которые в основном реализованы в зоне обнаружения, формируемой с учетом энергетических характеристик РТС СН (дальность обнаружения, точность определения координат, помехозащищенность);

на учёте эксплуатационно-технических характеристик, определяющих возможности по реализации боевых возможностей РТС СН. К ним относятся характеристики надежности (безотказность, ремонтопригодность, долговечность), стоимостные характеристики РТС СН (стоимость разработки, производства и эксплуатации) и ресурсные возможности по финансированию, которые зависят от используемой элементной базы, конструктивных особенностей РТС $\mathrm{CH}$, приспособленности к проведению ремонтов и др.

Процесс подбора параметров существенно облегчается введением ограничений на пределы изменения параметров. Отбор комплектов параметров осуществляется с помощью специально разработанных компьютерных программ.

Предложенный подход целесообразно использовать при модернизации существующих и проектировании новых РТС СН наблюдения за воздушной обстановкой.

\section{Список литературы}

[1] Бердышев В.П., Куликов В.Н., Мойсеенко П.Г и др. Системотехнические основы построения вооружения РТВ. Часть 1. Радиолокационная система РТВ. Получение и обработка радиолокачионной информации. Воздействие активных помех и защита от них / под ред. В. П. Бердышева. Тверь, ВА ВКО, 2008, 224 с. [Berdyshev V.P., Kulikov V.N., Mojseenko P.G et. al. Sistemotehnicheskie osnovy postroenija vooruzhenija RTF. Part 1. Radiolokacionnaja sistema RTF. Poluchenie i obrabotka radiolokacionnoj informacii. Vozdejstvie aktivnyh pomeh i zashhita ot nih. Ed. By V.P. Berdyshev. Tver', VA VKO, 2008, 224 p. (in Russian)]

[2] Бердышев В.П., Куликов В.Н., Кузнецов В.В. и др. Системотехнические основы построения вооружения РТВ. Часть 2. Воздействие пассивных помех и защита от них. Основы построения обзорных радиотехнических средств / под ред. В. П. Бердышева. Тверь, ВА ВКО, 2008, 248 c. [Berdishev V.P. Kulikov V.N. Kuznecov V.V. et. al. Sistemotehnicheskie osnovi postroeniya voorujeniya RTV. Part 2. Vozdeistvie passivnih pomeh i zaschita ot nih. Osnovi postroeniya obzornih radiotehnicheskih sredstv. Ed. By V.P. Berdishev. Tver', VA VKO, 2008, 248 p. (in Russian)] 
[3] Бердышев В.П., Гарин Е.Н., Фомин А.Н. и др. Радиолокационные системы / под ред. В.П. Бердышева. Красноярск, Сиб. федер. ун-т, 2011, 400 с. [ Berdishev V.P., Garin E.N., Fomin A.N. et. al. Radar systems. Ed. By V.P. Berdishev, Krasnoyarsk, Sib. feder. un-t, 2011, 400 p. (in Russian)]

[4] Тяпкин В.Н., Бердышев В.П., Гарин Е.Н. и др. Основы построения РЛС РТВ / под ред. B.Н. Тяпкина. Красноярск, Сиб. федер. ун-т, 2011, 536 с.[ Tyapkin V.N., Berdishev V.P., Garin E.N. et. al. Fundamentals of RTF radar. Ed. By V.N. Tyapkin. Krasnoyarsk, Sib. feder. Un-t, 2011, 536 p. (in Russian)]

[5] Радиотехнические системы / под ред. Ю.М. Казаринова. М.: Высшая школа, 1990, 496 c. [Radio-technical systems. Ed. By Yu.M. Kazarinov. Moscow, Visshaya shkola, 1990, 496 p. (in Russian)]

[6] Справочник офицера ПВО / под ред. Г.В. Зимина. М.: Воениздат, 1981, 432 с. [Manual air defense officer. Ed. By G.V. Zimin. Moscow, Voenizdat, 1981, 432 p. (in Russian)]

[7] Барзилович Е.Ю. Модели технического обслуживания сложных систем. М.: Высшая школа, 1982, 231 с. [Barzilovich E.Yu. Models maintenance of complex systems. Moscow, Visshaya shkola, 1982, 231 p. (in Russian)]

[8] Бакулев П.А., Степин В.М. Методы и устройства селекиии движущихся иелей. М.: Радио и связь, 1986, 288 с. [Bakulev P.A. Stepin V.M. Methods and moving target indication device. Moscow, Radio i svyaz, 1986, 288 p. (Russian)]

[9] Radar handbook. Ed. By Merrill I.Skolnik. - 2nd ed. McGraw-Hill, 2000, 780 p. (in USA)

[10] Григорьев Б.М., Губанов А.В., Крылов А.А. и др. Радиолокаиионное обеспечение полетов военной авиации. Системотехника и приложения / под ред. В.Ю. Кузьменкова. Черноголовка, РИО ИПХФ РАН, 2015, 304 с.[ Grigorev B.M., Gubanov A.V., Krilov A.A. et. al. Radar software flights of military aircraft. System engineering and applications. Ed. By V.Yu. Kuzmenkov. Chernogolovka, RIO IPHF RAN, 2015, 304 p. (in Russian)] 